\title{
The Drug Treatment Outcomes Research Study (DTORS): Research Design and Baseline Data
}

\author{
Michael Donmall ${ }^{1}$, Andrew Jones ${ }^{1}$, Samantha Weston ${ }^{2}$, Linda Davies ${ }^{3}$, Karen P. Hayhurst ${ }^{*}{ }^{1}$ and \\ Tim Millar ${ }^{1}$ \\ ${ }^{I}$ National Drug Evidence Centre (NDEC), Health Sciences Research Group, School of Community Based Medicine, \\ University of Manchester, Manchester, UK \\ ${ }^{2}$ School of Sociology \& Criminology, Keele University, UK \\ ${ }^{3}$ Health Economics Research, Health Sciences Research Group, School of Community Based Medicine, University of \\ Manchester, Manchester, UK
}

\begin{abstract}
The Drug Treatment Outcomes Research Study (DTORS) is the more recent of two such major English studies. Over the past decade, a substantial policy shift has emphasised the role of treatment in diverting drug misusing offenders from the criminal justice system. At the same time, changes in the drug-using population, particularly increasing levels of crack cocaine use, have led to an acute need to evaluate the extent to which drug treatment works. DTORS consists of three components: the main, quantitative element tracking the treatment progress of $\mathrm{N}=1,796$ drug treatment seekers; qualitative work using data from a sample of treatment seekers and treatment providers; and a cost effectiveness analysis. This paper provides an overview of the methods used for the main quantitative element; a longitudinal, nationwide, multisite, observational, cohort study using survey interviews to assess the impact of treatment on drug use, offending, and health. An overview of the DTORS baseline sample is provided and compared with the target population of drug treatment seekers in England. Participants were drug users seeking treatment from community based or residential treatment services, assessed at baseline and followed up over a 12-month period. The baseline DTORS sample was predominantly male (73\%) and aged 25 to 34 (47\%). Primary problem drugs included heroin (57\%) and crack (12\%) with drugs used in the month prior to baseline having a mean value of $£ 1,213$. $72 \%$ committed offences in the 12 months before recruitment, most commonly shoplifting or buying and selling stolen goods.
\end{abstract}

Keywords: baseline survey, data collection, drug dependence, methods, research design, treatment.

\section{INTRODUCTION}

The Drug Treatment Outcomes Research Study (DTORS) [1] is the most recent of two major large-scale English outcomes studies in this field. DTORS seeks to evaluate treatment for individuals with problems of drug misuse in the context of recent policy changes that have focused on diverting drug misusing offenders from the criminal justice system (CJS) into treatment and the national growth in use of crack cocaine.

The nature of drug misuse in England has changed over the past decade. National data show 14\% [2] of treatment entrants using crack and/ or cocaine in 1998. This proportion had increased to $24 \%$ [3] by 2001, with recent data suggesting that $35 \%$ of treatment entrants use crack in England and up to $52 \%$ across nine English Government Office Regions [4]. Crack users may have differing treatment needs than clients presenting with problematic use of other drugs and crack use has elicited a wide and disparate range of treatment responses $[5,6]$.

\footnotetext{
*Address correspondence to this author at the National Drug Evidence Centre (NDEC), Health Sciences Research Group, School of Community Based Medicine, University of Manchester, Manchester, UK;

Tel: +44 (0) 161275 8365; Fax: +44 (0) 161275 1668;

E-mails: karen.hayhurst@manchester.ac.uk, m.donmall@manchester.ac.uk
}

In addition to changes in the nature of the English drug treatment population the approach to drug treatment referral has also changed. The widespread introduction of diversionary schemes for drug misusers in contact with the CJS, has allowed treatment to be offered to large numbers of people who may not otherwise have sought it [7]. At the time of DTORS $24 \%$ of treatment seekers were CJS-referred [8]. In England and Wales, the high proportion of offenders who misuse drugs [9] has led to the development of the Drug Interventions Programme (DIP); referring offenders from the CJS to advance people "out of crime and into treatment" [10]. DIP built on diversionary schemes such as Arrest Referral, known to have resulted in substantial numbers of drug misusing offenders seeking treatment $[11,12]$. Whether the expansion of these 'funnels' into treatment has introduced greater heterogeneity in the clients of drug services and whether treatment works for those referred from the CJS remain crucial questions. CJS-referred clients may present particular challenges to treatment services by virtue of the seriousness of their drug problems $[13,14]$ and in terms of adherence to treatment protocols, co-operation with agency staff, continuing use of drugs, continuing offending behaviour and rates of relapse, which may adversely affect treatment outcomes in this group [15].

With substantial expenditure on services for drug misusers and apparent increases, year on year, in the number of drug users in treatment there is an acute need to evaluate whether 
current drug treatment works for the changing drug treatment population in England. DTORS was therefore designed to provide information about the effectiveness of drug treatment currently available across England and examine whether, and how, these changes to the drug treatment population impact upon treatment outcomes. The study included three distinct elements: a quantitative follow-up study; a qualitative study and an economic evaluation [1,16-18]. The purpose of this paper is to provide an overview of the research methods used in the main quantitative aspect of DTORS and describe the baseline data, in particular, how the baseline sample reflects the target drug treatment seeking population.

\section{METHODS}

\section{Research Design}

Further details of the design of DTORS are available elsewhere [1, 19]. DTORS was a nationwide, multi-site, observational, prospective, longitudinal, cohort study designed primarily to assess the impact of drug treatment on:

- Levels of drug and alcohol use

- Offending behaviour

- $\quad$ Physical and mental health

- Wider social outcomes

Baseline interviews took place with treatment seekers presenting for community based specialised and structured treatment (known in England as Tier 3, and referred to in this paper as community based treatment) or residential specialised and structured treatment (known in England as Tier 4, and referred to in this paper as residential treatment), followed up over a 12-month period. Structured drug treatment is defined as that which, "follows assessment and is delivered according to a care plan, with clear goals, which is regularly reviewed with the client" [20]. Clients normally receive an initial assessment at first face-to-face contact with a treatment agency. Structured treatment is likely to start a number of days or weeks later.

\section{Ethical Approval}

Multi-site NHS Research Ethics approval was obtained for the study.

\section{Outcomes Assessment}

Data collection was via a standardised questionnaire, developed for the study and constrained by Steering Group consensus to limit mean interview length to 45 minutes. Information was gathered on: demographics and accommodation; route of referral; previous treatment history; motivation and goals; drug use; risk behaviour; offending behaviour; mental health; physical health; income; and education. Table 1 shows data collected at baseline and follow-up.

The following standardised and previously validated instruments were included in the questionnaire: Circumstances, Motivation and Readiness scale (CMRS) [21]; Severity of Dependence Scale (SDS) [22]; and SF12 [23]. Other items were adapted from well-known instruments including the Maudsley Addiction Profile (MAP) [24] and the Injecting Risk Questionnaire (IRQ) [25]. Sections covering accommodation, drug use, treatment pathways, goals, and motivation were subject to cognitive testing in four non-statutory agencies, leading to some question rewording. Full pilot testing of the complete survey tool was carried out in treatment agencies within four Drug Action Teams (DATs - the administrative areas responsible for

Table 1. Questionnaire Breakdown

\begin{tabular}{|c|c|c|c|}
\hline Demographics & $\mathrm{X}$ & $\mathrm{X}$ & $\mathrm{X}$ \\
\hline Referral source & $\mathrm{X}$ & & \\
\hline Treatment history & $\mathrm{X}$ & & \\
\hline Aims and goals of treatment & $\mathrm{X}$ & $\mathrm{X}$ & $\mathrm{X}$ \\
\hline CMR (circumstances) & $\mathrm{X}$ & $\mathrm{X}$ & $\mathrm{X}$ \\
\hline CMR (motivation) & $\mathrm{X}$ & & \\
\hline CMR (readiness) & $\mathrm{X}$ & & \\
\hline Health risk behaviour & $\mathrm{X}$ & $\mathrm{X}$ & $\mathrm{X}$ \\
\hline Offending behaviour in last 12 months & $\mathrm{X}$ & & \\
\hline Offending behaviour in last 4 weeks & $\mathrm{X}$ & $\mathrm{X}$ & $\mathrm{X}$ \\
\hline Mental and physical health (SF12) & $\mathrm{X}$ & $\mathrm{X}$ & $\mathrm{X}$ \\
\hline Income and education & $\mathrm{X}$ & $\mathrm{X}$ & $\mathrm{X}$ \\
\hline
\end{tabular}


commissioning drug treatment provision), with results informing question ordering and wording [19]. All interviews used Computer Assisted Personal Interviewing (CAPI) with a trained interviewer reading questions from a laptop and inputting the respondent's answers. The option of self-completion was available for sensitive questions, such as risk-taking behaviour and offending.

\section{Sample Size and Power Calculation}

A power calculation indicated that a sample of $\mathrm{N}=2,600$ would have $90 \%$ power to detect a difference of $£ 25$ in change in weekly drug spend between CJS and non-CJS referred clients. This assumed a $30 \%$ loss to 12 -month follow-up [26], a within subject correlation of 0.2 , an intercluster correlation of $\rho=0.04$ [27] due to clustering of the sample within service providers, and a minority of participants (1:4) being CJS referrals. The chosen variable was an indicator of drug use intensity and associated drugrelated problems. The power of the sample was revisited in the light of the actual baseline sample of $\mathrm{N}=1,796$. With a $1: 2$ ratio of CJS to non-CJS referrals, a presumed $40 \%$ loss to (first) follow-up and a within subject correlation of 0.5 , the obtained sample had $89 \%$ power to detect a $£ 25$ difference in change in weekly drug spend between CJS and non-CJS clients between baseline and first follow-up [19].

\section{Sampling}

The study adopted a 3-stage sampling strategy (Table 2) aiming for a nationally representative sample of DATs, agencies, and clients. This strategy was supported by data from the National Drug Treatment Monitoring System (NDTMS) on the target population of national treatment seekers at the time of DTORS (Mar 2006 - Jan 2007). detoxification, residential rehabilitation, specialist prescribing, GP prescribing, structured counselling, and structured day care. Although most provide only some of these interventions, all were needed to ensure that the full range of interventions was represented.

\section{Participant Selection}

The baseline sample comprised those who sought treatment, regardless of whether they started treatment. All individuals newly seeking treatment at each agency within a nine week sampling window were eligible for inclusion. Inclusion criteria designed to facilitate follow-up were not used, since this approach increases the risk of significant sampling bias. This is in contrast to previous studies that, prior to DTORS, were the main source of evidence. For example, stability of contact address was used in NTORS [4] and restrictions were placed on eligibility for follow-up in DATOS [28]. Eligibility criteria were:

- Individuals seeking treatment within a specified sample window

- $\quad$ Aged 18 years or over

- $\quad$ Presenting with a drug use problem

- $\quad$ Requesting treatment for their drug problem

\section{Data Collection Procedure}

Interviews took place between February 2006 and March 2007. A total of 262 professional interviewers gathered data at baseline. Each attended a one-day briefing run by the research team, which included guidance on recruitment; further briefings were held throughout the project. Interviewer standardisation was aided by the use of consistent question wording and prompts. Interviews took place as close to the date of presentation as possible ( $72 \%$ within two weeks).

Table 2. Sampling Strategy \& Characteristics of Sample

\begin{tabular}{|c|c|c|c|}
\hline Stage & Eligible for Inclusion & Target Sample & Achieved Sample \\
\hline \hline 1. DATS & 100 of 149 DATs in England & & 94 \\
\hline 2. Agencies & $\begin{array}{c}\text { All agencies within participating DATs providing community } \\
\text { based or residential treatment }\end{array}$ & Average 6 per DAT, 628 in total & $\mathrm{N}=342$ \\
\hline 3. Clients & $\begin{array}{c}\text { All clients of participating agencies, presenting for a new } \\
\text { episode of treatment within the sample window (4-9 weeks) }\end{array}$ & $\begin{array}{c}\text { Average 3 per agency per week, approx. } \\
10000 \text { in total }\end{array}$ & $\begin{array}{c}\mathrm{N}=1,796,73 \% \text { male, } 72 \% \\
25-44 \text { yrs, } 89 \% \text { white }\end{array}$ \\
\hline
\end{tabular}

\section{DAT Selection}

Stage one involved selecting 100 DATs from the 149 in England; this large proportion (67\%) was chosen to minimise the burden on individual DATs and increase sampling power by decreasing the effect of clustering. DATs were selected by grouping all 149 into tertiles based on levels of CJS referrals reported to NDTMS. One hundred DATs were then randomly sampled across the tertiles. Where DATs declined to participate, a replacement DAT was randomly selected from the same tertile as the original DAT.

\section{Agency Selection}

All agencies (statutory and non-statutory) providing community based or residential treatments within selected DATs were approached. These provided inpatient

\section{Saliva Testing}

To validate self-reported drug use, saliva specimens were collected from a randomly selected sample of participants to test for use of heroin, other opiates, cocaine, or crack cocaine in the previous two days.

\section{CHARACTERISTICS OF BASELINE SAMPLE}

Table 3 sets out the key characteristics of the baseline sample. Table 4 compares the DTORS sample $(\mathrm{N}=1,796)$ with the target drug treatment population, using NDTMS data on new treatment seekers $(\mathrm{N}=86,908)$ during the same time period. NDTMS routinely collects community based and residential treatment service data across England. The age and gender profile was as expected in a drug treatment sample (73\% male, median age $32 \mathrm{yr}$ ) [2]. 
The DTORS baseline sample was the same in terms of gender, but was slightly older, than the target population, with a lower representation of clients from the youngest age group (18-24yr) and a larger representation in the age group $35-44 y r$. A similar majority of treatment seekers from a white background was seen in both samples.

The majority of both samples used heroin as their primary problem drug (self-defined by the client) although this proportion was lower in DTORS (57\% vs 65\%). A lower proportion of DTORS also reported that cocaine or cannabis were primary problem drugs, whereas the proportion defining crack as their primary problem was higher $(12 \% \mathrm{vs}$ $8 \%$ ). Note that NDTMS employs a treatment-specific definition of primary substance, whereas DTORS uses that self-defined by the client. DTORS stratified the sample across tertiles of known CJS referral to avoid the risk of underrepresentation. Careful checks were also made on the presence of CJS involvement in referral mechanisms to ensure that informal referrals from CJS settings were not recorded as self referrals.

Table 3. Key Characteristics of Baseline Sample

\begin{tabular}{|c|c|}
\hline Measure & $\begin{array}{c}\text { Baseline DTORS } \\
\mathbf{N}=1,796\end{array}$ \\
\hline Age (yr): Mean (SD) & $32.7(7.7)$ \\
\hline $18-24$ & $256(14)$ \\
\hline $25-34$ & $839(47)$ \\
\hline $35-44$ & $552(31)$ \\
\hline $45-54$ & $118(7)$ \\
\hline $55+$ & $15(<1)$ \\
\hline Male Gender & $1314(73)$ \\
\hline Ethnicity & \\
\hline White & $1569(87)$ \\
\hline Black & $64(4)$ \\
\hline Mixed & $71(4)$ \\
\hline Asian & $56(3)$ \\
\hline Other & $31(2)$ \\
\hline Age finished education (yr) & Median $=16$ \\
\hline $10-15$ & $665(37)$ \\
\hline $16-17$ & $886(49)$ \\
\hline $18+$ & $203(11)$ \\
\hline Family circumstances & \\
\hline Married or live with partner & $676(38)$ \\
\hline Partner takes drugs & $268(40)^{1}$ \\
\hline Have children under $16^{2}$ & $918(51)$ \\
\hline Live apart from children under 16 & $685(75)^{3}$ \\
\hline
\end{tabular}

\section{Drug Use}

Heroin (64\%) was the most commonly used drug in the four weeks prior to baseline (see Fig. 1). Almost a half of respondents had used crack, or cannabis, or alcohol. Benzodiazepines were used by $25 \%$, other opiates by $22 \%$, unprescribed methadone by $18 \%$ and cocaine powder by $15 \%$. The majority (69\%) of clients reported poly-drug use (two or more drugs, excluding alcohol) at baseline.

\section{Table 4. DTORS \& NDTMS Samples}

\begin{tabular}{|c|c|c|}
\hline & $\begin{array}{c}\text { DTORS } \\
\text { Baseline } \\
\mathbf{N}=1,796(\%)\end{array}$ & $\begin{array}{c}\text { NDTMS } \\
\text { New Treatment } \\
\text { Population } \\
\text { N=86,908 }(\%)\end{array}$ \\
\hline Age (yr) & & \\
\hline $18-24$ & 14.3 & 19.9 \\
\hline $25-34$ & 46.7 & 45.6 \\
\hline $35-44$ & 30.7 & 27.1 \\
\hline $45+$ & 7.4 & 7.3 \\
\hline Mean age & 32.7 & 31.8 \\
\hline Male Gender & 73.2 & 73.3 \\
\hline Ethnicity & & \\
\hline White & 87.4 & 87.7 \\
\hline Black & 3.6 & 4.4 \\
\hline Mixed & 4.0 & 2.7 \\
\hline Asian & 3.1 & 4.0 \\
\hline Other & 1.7 & 1.2 \\
\hline CJS Referral Source & 34.5 & 26.0 \\
\hline Main problem drug & & \\
\hline Heroin & 56.8 & 65.3 \\
\hline Other opiates & 1.1 & 3.1 \\
\hline Crack cocaine & 11.6 & 7.5 \\
\hline Cocaine powder & 2.6 & 7.5 \\
\hline Unprescribed Amphetamines & 2.5 & 3.8 \\
\hline Cannabis & 4.2 & 8.6 \\
\hline Ecstasy & 0.4 & 0.4 \\
\hline Hallucinogens & 0.3 & 0.1 \\
\hline Alcohol & 5.5 & ----- \\
\hline Unprescribed Benzodiazepines & 0.7 & 1.2 \\
\hline Solvents & 0.1 & 0.1 \\
\hline
\end{tabular}

Heroin, crack, or alcohol, were the drugs most likely to be used problematically (self-defined as currently causing a problem by the client) by respondents $(72 \%, 46 \%$ and $23 \%$ respectively). The majority (57\%) defined heroin as their primary problem drug, with a further $12 \%$ defining crack as their primary problem. A mean Severity of Dependence Score for heroin of 9.1 (SD 3.7) was observed (max score 15). 


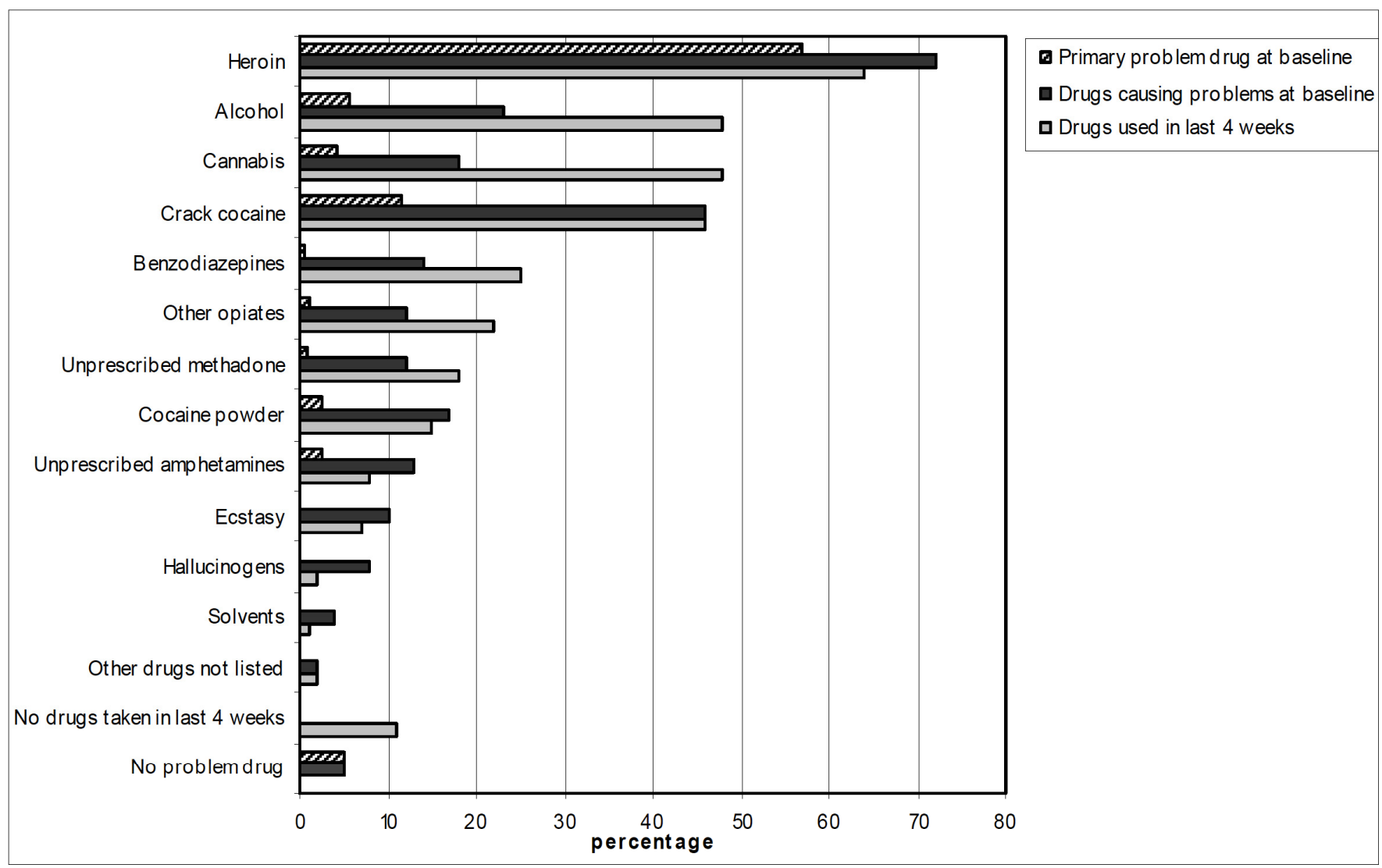

Fig. (1). Drugs used last four weeks, currently causing problems, and causing most problems.

Respondents used drugs with a mean value of $£ 1,213(95 \%$ CI $£ 1,126$ to $£ 1,300$ ) in the four weeks prior to baseline.

\section{Offending Behaviour}

Fig. (2) shows self-reported offending behaviour over the 12 month, and four week, period prior to baseline. Forty-two per cent acknowledged one or more offences during the previous four weeks. Shoplifting was the most common crime $(26 \%)$, followed by buying or selling stolen goods (19\%), dealing drugs (9\%) and other stealing (8\%).

In the previous 12 months, $72 \%$ had committed a crime, with $47 \%$ reporting shoplifting, $41 \%$ buying or selling stolen goods, 24\% other stealing and 23\% dealing drugs (Fig. 2). Respondents committing acquisitive offences obtained a median of $£ 130$ (IQR 725) during the previous four weeks (money made, including cash value of any goods obtained). Nearly a quarter $(22 \%)$ of the sample said that they had offended in the last four weeks to buy or obtain drugs and $17 \%$ had offended whilst under the influence of drugs.

\section{Health and Risk Behaviour}

Most respondents said their health was fair $(31 \%)$, or good $(29 \%)$ but $18 \%$ rated their health as poor. Mean scores obtained for the SF-12 were 47.5 (SD 11.1, range 11-66) for physical health (UK norm 51) and 35.4 (SD 12.4, range 664) for mental health (UK norm 52). Twenty-eight per cent had previously received treatment for physical health problems, $23 \%$ had received a mental health diagnosis, $37 \%$ had been referred for mental health treatment, and $28 \%$ had received mental health treatment (12\% in the last 3 months).
Nine per cent reported having experienced an overdose in the last three months and over half of the sample (52\%) was at risk of a poly-drug overdose (taking opiates together with other opiates, benzodiazepines or alcohol). A third of the sample $(33 \%)$ had injected drugs in the previous four weeks, and among current injectors, $47 \%$ reported sharing syringes or other injecting equipment. Almost a half of the sample $(46 \%)$ had had unprotected sex in the last three months.

\section{Drug Use History, Treatment History, Treatment Goals and Motivation}

Participants had a mean age of first drug use of $16 \mathrm{yr}$ (95\% CI $15.9 \mathrm{yr}$ to $16.6 \mathrm{yr}$ ), with drug use becoming problematic at $21 \mathrm{yr}(95 \%$ CI $20.4 \mathrm{yr}$ to $21.1 \mathrm{yr})$. Structured drug treatment was first received at $25 \mathrm{yr}(95 \%$ CI $25.1 \mathrm{yr}$ to $25.9 \mathrm{yr}$ ), with time between onset of (self-defined) problem use and the current planned treatment averaging 13yr $(95 \%$ CI $12.2 \mathrm{yr}$ to $13.0 \mathrm{yr})$. The majority $(72 \%)$ reported previous community based or residential drug treatment with prior experience of community prescribing most common (59\%). Twenty-six per cent had experienced inpatient detoxification treatment, $24 \%$ residential rehabilitation, and $19 \%$ community based non-prescribing treatment.

The most common treatment goal was to 'stop taking all drugs' (71\%). The second most commonly held goal was to 'sort life out' (47\%), with other goals including to 'improve health' (20\%), 'improve employment chances' (19\%), and 'improve relationships' (16\%). At baseline, only 7\% thought it unlikely that their treatment goals would be achieved by first follow-up. High average scores across the sample were 


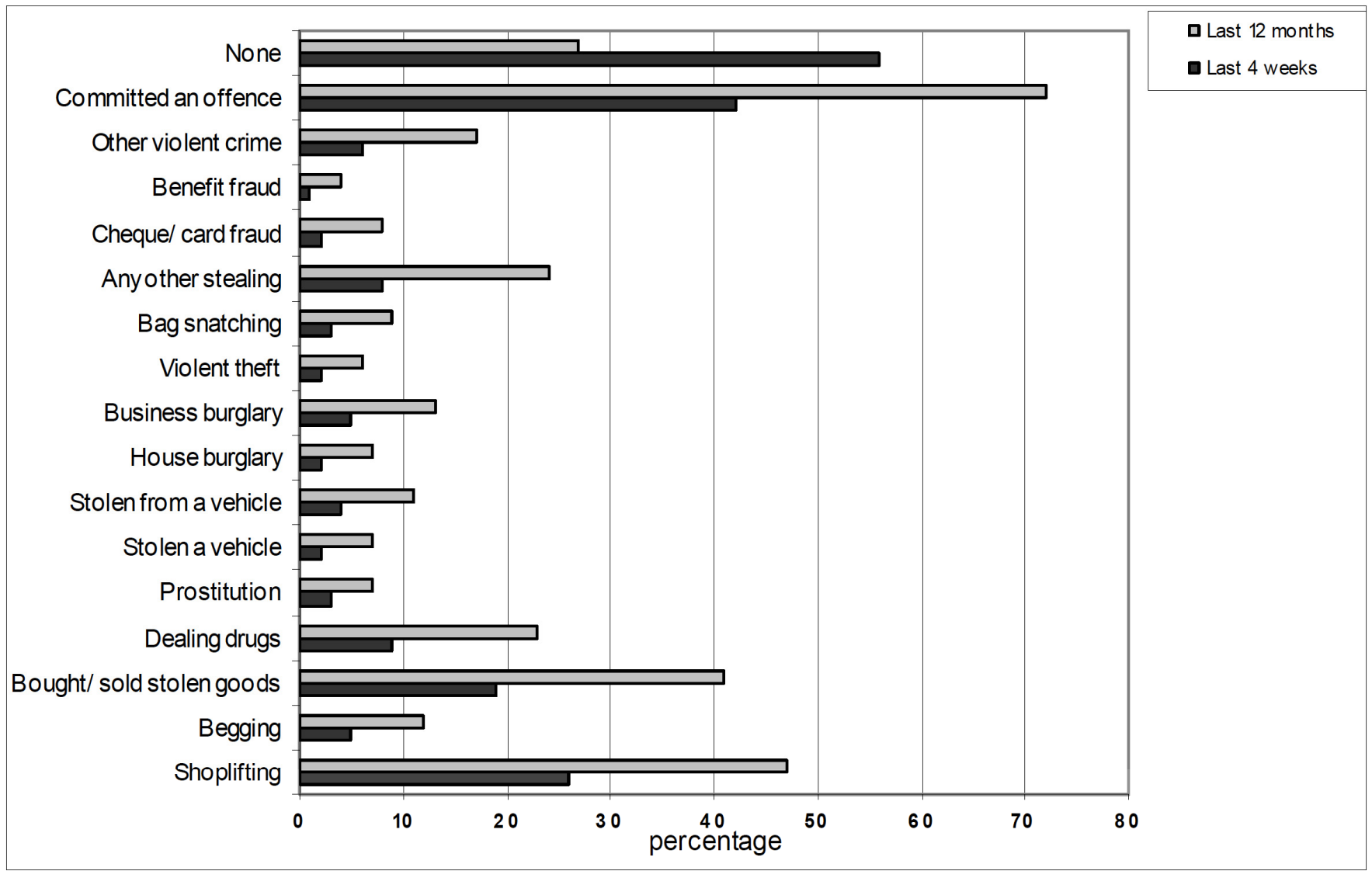

Fig. (2). Offences committed last 12 months, last 4 weeks.

obtained for two of the four CMR subscales indicating high readiness (mean of 31 out of a maximum of 35) and motivation for treatment $(22 / 25)$, a low level (12/15, scores reversed) of external influences to leave treatment and a midrange level (9/15) of external pressures (legal and family) to enter treatment. The majority reported wanting help with their drug use (94\%) and other aspects of their life $(77 \%)$ either "very much indeed" or "quite a lot".

\section{CJS-Referral vs Non CJS-Referral Differences}

Statistically significant differences between CJS-referred participants and those referred via other routes are set out in Table 5. Referral involved a CJS component for $35 \%$ of clients, with a third of these attending treatment as a bail condition. Demographic differences between the two groups of interest include CJS-referred clients finishing education earlier (44\% vs 34\% before $16 \mathrm{yr})$ and lacking stability of address $(39 \%$ vs $22 \%$ in any unstable accommodation in previous month). CJS-referred clients were more likely to report problematic use of heroin $(75 \%$ vs $70 \%)$, crack $(56 \%$ vs $40 \%)$, ecstasy (12\% vs $9 \%$ ) and benzodiazepines (17\% vs $13 \%$ ) and more likely to report crack cocaine as their primary problem drug (15\% vs $10 \%)$ with a higher crack dependency score (Mean 6.6 vs 5.8).

\section{Crack User vs Non-Crack User Differences}

Crack cocaine use ${ }^{1}$ was reported by $61 \%$ of the baseline sample; Table 6 sets out statistically significant differences

${ }^{1}$ Use in the last month or self-defined problematic use. between this group and non crack users in the sample. Crack users also lacked stability of address (34\% vs 18\% in any unstable accommodation in previous month) and had a much higher drug spend (Median $£ 575$ vs $£ 217$ in previous month). Crack users were more likely than non crack users to report problematic use of a number of other drugs; heroin $(82 \% v s$ $56 \%)$, unprescribed methadone $(16 \%$ vs $5 \%)$, other opiates $(15 \%$ vs $6 \%)$, cocaine $(20 \%$ vs $13 \%)$, unprescribed amphetamine $(15 \%$ vs $11 \%)$, ecstasy $(13 \%$ vs $5 \%)$, hallucinogens $(12 \%$ vs $2 \%)$, benzodiazepines (19\% vs $6 \%)$, solvents $(6 \%$ vs $2 \%)$ and alcohol (26\% vs 19\%). They were more likely to report heroin as their primary problem drug $(61 \%$ vs $51 \%)$ with a higher heroin dependency score (Mean 6.6 vs 4.5). Crack using clients were more likely to have committed all categories of crime in the previous 12 months, apart from benefit fraud and other violent crime. Crack users had a longer length of time between their drug use becoming problematic and the current episode of treatment (13vs $4 \mathrm{yr}$ ) but they had higher scores on the CMR subscales.

\section{DISCUSSION}

DTORS is the largest drug treatment outcomes study conducted in England to date. The study, which took its sample from the whole of England, updates the evidence base, especially important in the context of current policy on reducing the problems associated with drug misuse and known changes in patterns of drug use towards increases in problematic crack use, as confirmed by the DTORS baseline sample. While heroin was the primary drug for the majority, crack use was also common and more so than in earlier 
Table 5. CJS-Referred \& Non CJS-Referred DTORS Samples: Significant Differences

\begin{tabular}{|c|c|c|c|}
\hline & CJS Sample N=620 (35\%) & Non CJS Sample N=1,176 (65\%) & $p$ \\
\hline Age (yr), Mean (SD) & $31.8(7.1)$ & $32.8(8.9)$ & 0.014 \\
\hline Male gender & $500(81)$ & $814(69)$ & $<0.001$ \\
\hline White ethnicity & $525(85)$ & $1044(89)$ & 0.013 \\
\hline Finished education younger than $16 \mathrm{yr}$ & $270(44)$ & $395(34)$ & $<0.001$ \\
\hline Any unstable accommodation previous $4 \mathrm{wk}$ & $239(39)$ & $258(22)$ & $<0.001$ \\
\hline In employment & $25(4)$ & $142(12)$ & $<0.001$ \\
\hline Legitimate income previous $4 \mathrm{wk}$ & Median $£ 228$ & Median $£ 280$ & $<0.001$ \\
\hline Time between problem use and current treatment, Mean (SD) & $17.1(11.0)$ & $18.4(12.5)$ & 0.032 \\
\hline \multicolumn{4}{|l|}{ Drugs reported as problematic } \\
\hline Heroin & $466(75)$ & $823(70)$ & 0.020 \\
\hline Crack cocaine & $346(56)$ & $474(40)$ & $<0.001$ \\
\hline Ecstasy & $74(12)$ & $103(9)$ & 0.032 \\
\hline Unprescribed Benzodiazepines & $105(17)$ & $147(13)$ & 0.010 \\
\hline Primary problem drug $=$ Crack & $92(15)$ & $116(10)$ & 0.002 \\
\hline Crack dependency score, Mean (SD) & $6.6(4.7)$ & $5.8(4.7)$ & 0.023 \\
\hline \multicolumn{4}{|l|}{ Offending previous $12 \mathrm{~m}$} \\
\hline Shoplifting & $360(58)$ & $487(41)$ & $<0.001$ \\
\hline Bought/sold stolen goods & $315(51)$ & $429(37)$ & $<0.001$ \\
\hline Stolen a vehicle & $60(10)$ & $67(6)$ & 0.002 \\
\hline Stolen from a vehicle & $96(16)$ & $97(8)$ & $<0.001$ \\
\hline House burglary & $72(12)$ & $60(5)$ & $<0.001$ \\
\hline Business burglary & $124(20)$ & $107(9)$ & $<0.001$ \\
\hline Violent theft & $59(10)$ & $15(2)$ & $<0.001$ \\
\hline Bag-snatching & $76(12)$ & $84(7)$ & $<0.001$ \\
\hline Any other stealing & $183(30)$ & $241(21)$ & $<0.001$ \\
\hline Cheque/card fraud & $65(11)$ & $85(7)$ & 0.018 \\
\hline Benefit fraud & $36(6)$ & $42(4)$ & 0.039 \\
\hline SF-12 physical health score & $48.2(10.8)$ & $47.1(11.3)$ & 0.008 \\
\hline SF-12 mental health score & $38.2(12.5)$ & $33.8(12.1)$ & $<0.001$ \\
\hline Health rating of "poor" & $93(15)$ & $236(20)$ & 0.008 \\
\hline Previous mental health treatment & $139(22)$ & $365(31)$ & $<0.001$ \\
\hline \multicolumn{4}{|l|}{ CMR subscale, Mean (SD) } \\
\hline External pressures to enter treatment & $10.4(2.7)$ & $8.8(3.1)$ & $<0.001$ \\
\hline \multicolumn{4}{|l|}{ Treatment goals } \\
\hline Sort out accommodation & $76(12)$ & $105(9)$ & 0.026 \\
\hline Avoid a sentence & $43(7)$ & $33(3)$ & $<0.001$ \\
\hline
\end{tabular}

NB. number (\%) unless stated otherwise.

studies. In addition, a number of negative health indicators in the sample were highlighted, for example, substantial proportions shared syringes or other injecting equipment, had a risk of overdose, reported previous treatment for physical health problems or a previous referral for mental health treatment.
DTORS was an observational, longitudinal cohort study. Study limitations in relation to necessary study design constraints, were therefore shared with previous drug treatment outcome studies. The absence of a control group meant that outcomes could not be compared with a group not receiving structured drug treatment; findings were therefore suggestive of outcomes associated with treatment rather than evidence of causation. As with previous studies, the design 
of DTORS has a number of inherent biases. As an observational cohort study, participants were assigned to treatment modalities on the basis of clinical need, suitability and availability. Given such non-random assignment these studies are not able to conclude whether any particular type of drug treatment is more effective than any other. Nevertheless, the DTORS sample is large enough to have sufficient power to detect a pre-defined difference in change in drug spend between CJS and non-CJS groups and the sampling strategy ensured that the full range of treatment services available in each DAT was represented, as were patterns of CJS referral. In contrast to previous studies, DTORS was designed to focus on treatment seekers rather than treatment entrants. Studies focusing on treatment entrants have an inherent bias towards those stable enough to take up treatment. This feature of the study will have impacted upon response rates as some participants will not have had the stabilising influence of treatment to facilitate follow up.

The target interview length (45 minutes) introduced constraints on the choice of outcome measures, although the questionnaire was comprehensive in its coverage and subject to piloting and cognitive testing prior to use. DTORS was reliant on the accuracy of self-report data, demonstrated to have a reasonable degree of correspondence with objective measures [29,30]. Saliva test checks were used in a random subsample of respondents. Steps were also taken to encourage participants to supply accurate responses, most importantly, by using project interviewers who were entirely independent of treatment services. Previous studies, enlisted drug treatment workers to collect study data [31]; however, in that design clients would certainly have been aware of the possible negative impact on treatment associated with admitting continuing substance use to clinic staff.

The DTORS sample was broadly representative of the population starting drug treatment. The extent to which the DTORS sample is representative of the drug-using population, as a whole, is unknown, although indicators, such as the British Crime Survey [32], suggest that users of drugs other than opiates and crack cocaine are underrepresented in the drug treatment population.

The mean age of the DTORS sample at baseline (32.7 yr) was somewhat higher than that in NTORS (29.3 yr), consistent with expectations of an ageing drug treatment population [33]. Similar proportions of clients were male (73\% vs $74 \%)$ and white (87\% vs $91 \%)$. As in previous drug outcome studies heroin dependence was reported as the primary problem by the majority of DTORS respondents, alongside significant poly-drug use. Crack cocaine, cannabis, or alcohol was commonly used and despite the sample being characterised by problematic use of heroin, a sizeable minority $(12 \%)$ reported crack as their primary drug problem.

High rates of offending prior to treatment were reported; the most common crime being shoplifting, as was the case in the intake sample of previous studies [7]. Over one in five reported committing a crime in the month prior to baseline in order to buy or obtain drugs. Drugs with a mean value of $£ 1,213$ were used in the month prior to baseline and a median of $£ 130$ was obtained via acquisitive offences during the same time period.
Mean SF-12 baseline health scores were higher than those obtained in ATOS [34] at intake (47.5 vs 43.7 for physical health and 35.4 vs 31.3 for mental health). Psychological problems in the sample are indicated by over one in three having a previous referral for mental health treatment. It has long been known that at least $50 \%$ of clients in drug treatment have co-morbidity with psychiatric conditions [35-37]. This ongoing problem is in need of addressing further at a treatment level. The proportion experiencing an overdose (9\%) in the previous 90 days was similar to that seen in contemporary work elsewhere in the UK (11\%) [38] but over a half of the sample had a poly-drug overdose risk resulting from taking opiates together with other opiates, benzodiazepines or alcohol. A third of this sample report injecting drugs in the month prior to baseline. A higher proportion of DTORS current injectors $(47 \%)$ reported sharing syringes or other injecting equipment compared with $23.5 \%$ of injectors in NTORS [7]. Some have commented on a worrying complacency in England with regard to risks associated with sharing, especially HIV [39], following the major public health initiatives of the 1980s and '90s. Low levels of HIV awareness may have led to increased levels of risky behaviour. These findings should be of concern to policy makers and practitioners, alike. The proportion reporting poly-drug use was high $(69 \%$, excluding alcohol). European data point to $57 \%$ of problem drug users entering treatment being poly-drug users [40]. Data reported in Fig. (1), however, illustrate that use of other drugs is not considered to be a problem by the majority; rates of problematic use are considerably less than usage rates for a number of substances. It may be the case that clients are less likely to report use of certain substances as problematic if they believe that effective treatment for use of that substance is not available. Almost three-quarters of the baseline DTORS sample had prior experience of community based or residential drug treatment.

The CJS was involved with the referral of $35 \%$ of the sample. Treatment drop-out rates may be higher in CJSreferred clients $[12,41]$. Drug misusing offenders referred via the CJS might be expected to have different levels of treatment motivation; a strong predictor of a range of outcomes, including retention in treatment [42-47], raising questions about the effectiveness of drug treatment for this client group. It is worth noting the absence of reduced baseline motivation levels in CJS- compared with non CJSreferred clients in this sample. CJS-referred clients did differ in a number of ways from those referred into treatment via other routes; these differences may impact upon drug treatment outcomes. For example, CJS-referred clients were younger, with less formal education and higher levels of unstable accommodation. This group reported a greater proportion of problematic use of a number of substances; of importance is the higher proportion reporting crack as their primary problem drug. More positively, clients referred via the CJS had better health according to a number of indicators than other participants and did not have higher levels of risky behaviours.

A number of important differences were observed between crack using participants and other clients in the sample. Crack users had higher levels of problematic use of all drugs, apart from cannabis, and higher dependency on 
Table 6. Crack-Using \& Non Crack-Using DTORS Samples: Significant Differences

\begin{tabular}{|c|c|c|c|}
\hline & Crack Sample N=1,101 (61\%) & Non Crack Sample $N=695(39 \%)$ & $p$ \\
\hline Age (yr), Mean (SD) & $33.1(7.3)$ & $32.2(8.3)$ & 0.014 \\
\hline White ethnicity & $937(85)$ & $632(91)$ & $<0.001$ \\
\hline Any unstable accommodation previous $4 \mathrm{wk}$ & $369(34)$ & $128(18)$ & $<0.001$ \\
\hline In employment & $62(6)$ & $105(15)$ & $<0.001$ \\
\hline Legitimate income previous $4 \mathrm{wk}$ & Median $£ 252$ & Median $£ 295$ & $<0.001$ \\
\hline Drug spend previous $4 \mathrm{wk}$ & Median $£ 575$ & Median $£ 217$ & $<0.001$ \\
\hline Age at problematic drug use (yr), Mean (SD) & $20(6.3)$ & $21(6.5)$ & 0.008 \\
\hline Problem use to current treatment (yr), Mean (SD) & $13(7.0)$ & $4(5.9)$ & 0.003 \\
\hline \multicolumn{4}{|l|}{ Previous drug treatment } \\
\hline Inpatient detoxification & $341(31)$ & $124(18)$ & $<0.001$ \\
\hline Residential Rehabilitation & $316(29)$ & $114(16)$ & $<0.001$ \\
\hline Community prescribing & $701(64)$ & $361(52)$ & $<0.001$ \\
\hline Community non-prescribing & $246(22)$ & $102(15)$ & $<0.001$ \\
\hline \multicolumn{4}{|l|}{ Drugs reported as problematic } \\
\hline Heroin & $903(82)$ & $386(56)$ & $<0.001$ \\
\hline Unprescribed Methadone & $177(16)$ & $35(5)$ & $<0.001$ \\
\hline Other opiates & $168(15)$ & $40(6)$ & $<0.001$ \\
\hline Cocaine powder & $222(20)$ & $88(13)$ & $<0.001$ \\
\hline Unprescribed Amphetamine & $160(15)$ & $77(11)$ & 0.035 \\
\hline Ecstasy & $146(13)$ & $31(5)$ & $<0.001$ \\
\hline Hallucinogen & $128(12)$ & $15(2)$ & $<0.001$ \\
\hline Alcohol & $288(26)$ & $129(19)$ & $<0.001$ \\
\hline Unprescribed Benzodiazepines & $211(19)$ & $41(6)$ & $<0.001$ \\
\hline Solvents & $69(6)$ & $13(2)$ & $<0.001$ \\
\hline Primary problem drug $=$ Heroin & $666(61)$ & $355(51)$ & $<0.001$ \\
\hline Heroin dependency score, Mean (SD) & $6.6(5.1)$ & $4.5(5.2)$ & $<0.001$ \\
\hline \multicolumn{4}{|l|}{ Offending previous $12 \mathrm{~m}$} \\
\hline Shoplifting & $614(56)$ & $233(34)$ & $<0.001$ \\
\hline Begging & $169(15)$ & $45(7)$ & $<0.001$ \\
\hline Bought/sold stolen goods & $530(48)$ & $214(31)$ & $<0.001$ \\
\hline Drug dealing & $274(25)$ & $139(20)$ & 0.017 \\
\hline Prostitution & $97(9)$ & $26(4)$ & $<0.001$ \\
\hline Stolen a vehicle & $96(9)$ & $31(5)$ & 0.001 \\
\hline Stolen from a vehicle & $152(14)$ & $41(6)$ & $<0.001$ \\
\hline House burglary & $98(9)$ & $34(5)$ & 0.002 \\
\hline Business burglary & $178(16)$ & $53(8)$ & $<0.001$ \\
\hline Violent theft & $94(9)$ & $21(3)$ & $<0.001$ \\
\hline Bag-snatching & $128(12)$ & $32(5)$ & $<0.001$ \\
\hline Any other stealing & $307(28)$ & $117(17)$ & $<0.001$ \\
\hline Cheque/card fraud & $120(11)$ & $30(4)$ & $<0.001$ \\
\hline Income obtained from crime previous $4 \mathrm{wk}$ & Median $£ 200$ & Median $£ 60$ & $<0.001$ \\
\hline Committed crime to buy drugs & $309(28)$ & $92(13)$ & $<0.001$ \\
\hline Committed crime under influence of drugs & $243(22)$ & $68(10)$ & $<0.001$ \\
\hline Health rating of "poor" & $224(20)$ & $105(15)$ & 0.005 \\
\hline Poly-drug ${ }^{2}$ use & $895(81)$ & $338(49)$ & $<0.001$ \\
\hline Overdose in previous $3 \mathrm{~m}$ & $107(10)$ & $48(7)$ & 0.039 \\
\hline Sharing drug taking equipment & $212(19)$ & $65(9)$ & $<0.001$ \\
\hline Drug injecting & $428(39)$ & $165(24)$ & $<0.001$ \\
\hline Poly-drug overdose risk ${ }^{3}$ & $678(62)$ & $254(37)$ & $<0.001$ \\
\hline \multicolumn{4}{|l|}{ CMR subscales, Mean (SD) } \\
\hline External pressures to enter treatment & $9.8(3.0)$ & $8.7(3.0)$ & $<0.001$ \\
\hline External pressures to remain in treatment & $12.1(2.1)$ & $12.3(2.0)$ & 0.025 \\
\hline Motivation & $22.4(3.2)$ & $21.3(3.6)$ & $<0.001$ \\
\hline Readiness for treatment & $31.0(3.6)$ & $30.5(3.9)$ & 0.008 \\
\hline \multicolumn{4}{|l|}{ Treatment goals } \\
\hline Contact with children & $118(11)$ & $53(8)$ & 0.030 \\
\hline Sort out accommodation & $130(12)$ & $51(7)$ & 0.002 \\
\hline Avoid a sentence & $59(5)$ & $17(2)$ & 0.003 \\
\hline
\end{tabular}

NB. number (\%) unless stated otherwise. 
heroin, alongside their crack use, in addition to a median drug spend twice that of non crack users. The group also had higher levels of risky behaviour and lack of accommodation stability, along with higher levels of criminal involvement and a higher income from crime. Despite being characterised by patterns of drug use and behaviour which might impact negatively on successful treatment outcomes crack users had somewhat higher motivation scores than non crack users. As expected in a cohort of drug treatment seekers, almost threequarters of the DTORS sample, as a whole, reported the treatment goal of wanting to stop taking all drugs. High treatment readiness and motivation scores also characterised the total DTORS sample at baseline.

The DTORS baseline sample highlights the many problems associated with drug misuse that characterise individuals seeking drug treatment in England. Future DTORS papers will provide valuable information on the effectiveness of current structured drug treatment in reducing the harmful behaviours associated with problem drug use. In particular, future papers will examine treatment outcomes for CJS-referred, and crack-using participants. Comprising the most recent and robust national outcomes of structured drug treatment, with sampling representative of the situation in England, the findings of DTORS will significantly contribute to the evidence base for the development of national drug treatment policy decisions.

\section{ACKNOWLEDGEMENTS}

DTORS was commissioned and funded by the UK Home Office in 2005. We would like to thank the large number of individuals and organisations who made the study possible, specifically drug service clients; drug service staff; DATs; NHS Trusts; interviewers and operations staff; the Project Advisory Group; Alison Moody, Tracy Anderson, John D'Souza, Andrew Shaw and Tom Anderson at NatCen; Danni Poole at NDEC; Graham Dunn, Matthew Gittins, Chris Roberts and Islay Gemmell at The University of Manchester; and Anna Richardson, Nicola Singleton and May El Komy from the Home Office.

\section{COMPETING INTERESTS}

The authors declare that they have no competing interests.

\section{REFERENCES}

[1] Jones A, Donmall M, Millar T, et al. The Drug Treatment Outcomes Research Study (DTORS): Final outcomes report. London: Home Office 2009. Available at: http://rds.homeoffice. gov.uk/rds/pdfs 09/horr24c.pdf

[2] Department of Health. Statistics from the Regional Drug Misuse Databases for six months ending March 1998. London: Department of Health 1999.

[3] Department of Health. Statistics from the Regional Drug Misuse Databases for six months ending March 2001. London: Department of Health 2002.

[4] NTA. Statistics from the National Drug Treatment Monitoring System (NDTMS) 1 April 2008 - 31 March 2009. London: National Treatment Agency for Substance Misuse 2010.

[5] Marsden J, Eastwood B, Bradbury C, et al. Effectiveness of community treatments for heroin and crack cocaine addiction in England: a prospective, in-treatment cohort study. Lancet 2009; 374: $1262-70$.

[6] Seivewright N, Donmall M, Douglas J, Draycott T, Millar T. Cocaine misuse treatment in England. Int J Drug Policy 2000; 11: 203-15.
Gossop M, Marsden J, Stewart D, et al. Substance use, health and social problems of service users at 54 drug treatment agencies. Intake data from the National Treatment Outcome Research Study. Br J Psychiatry 1998; 173: 166-71.

[8] NTA. Statistics from the National Drug Treatment Monitoring System (NDTMS) 1 April 2006 - 31 March 2007. London: National Treatment Agency for Substance Misuse 2007.

[9] Holloway K, Bennett T, Lower C. Trends in drug use and offending: the results of the NEW-ADAM Programme 1999-2002. London: Home Office 2004.

[10] Home Office. Out of crime, into treatment: an introduction to the Drug Interventions Programme for treatment providers. London: Home Office 2007.

[11] Oerton J, Hunter G, Hickman M, et al. Arrest Referral in London police stations: characteristics of the first year. A key point of intervention for drug users? Drugs (Abingdon Engl) 2003; 10: 7385 .

[12] Sondhi A, O'Shea J, Williams T, Eds. Arrest Referral: emerging findings from the national monitoring and evaluation programme. London: Home Office 2002.

[13] Marshall GN, Hser Y-I. Characteristics of criminal justice and noncriminal justice clients receiving treatment for substance abuse. Addict Behav 2002; 27: 179-92.

[14] Stewart D, Gossop M, Marsden J, Rolfe A. Drug misuse and acquisitive crime among clients recruited to the National Treatment Outcome Research Study (NTORS). Crim Behav Ment Health 2000; 10: 10-20.

[15] Hubbard RL, Collins JJ, Harwood HJ, Marsden ME, Rachal JV. Role of criminal justice system referral for drug abuse treatment Unpublished report. North Carolina: Research Triangle Institute 1987.

[16] Barnard M, Webster S, O'Connor W, et al. The Drug Treatment Outcomes Research Study (DTORS): Qualitative Study. London: Home Office 2009. Available at: http://rds.homeoffice.gov.uk/rds/ pdfs09/horr26 c.pdf

[17] Davies L, Jones A, Vamvakas G, Dubourg R, Donmall M. The Drug Treatment Outcomes Research Study (DTORS): Costeffectiveness analysis. London: Home Office 2009. Available at: http://rds. homeoffice.gov.uk/rds/pdfs09/horr25c.pdf

[18] Donmall M, Jones A, Davies L, Barnard M. Summary of key findings from the Drug Treatment Outcomes Research Study (DTORS). London: Home Office 2009. Available at: http://rds.ho meoffice.gov. uk/rds/pdfs09/horr23.pdf

[19] Moody A, D'Souza J, Jones A, Weston S. Drug treatment outcomes research study (DTORS). Technical Report. London: National Centre for Social Research 2009. Available at: http://www.natcen.ac.uk/pzMedia/uploads/Downloadable/27749d4e$187 \mathrm{a}-4 \mathrm{ccf}-\mathrm{ab} 6 \mathrm{c}-\mathrm{c} 50 \mathrm{bad} 825 \mathrm{~b} 70$. doc

[20] NTA. Models of care for the treatment of drug misusers. Promoting quality, efficiency and effectiveness in drug misuse treatment services in England. London: National Treatment Agency for Substance Misuse 2002.

[21] De Leon G, Melnick G, Kressel D, Jainchill N. Circumstances, Motivation, Readiness and Suitability (the CMRS scales): predicting retention in therapeutic community treatment. Am J Drug Alcohol Abuse 1994; 20: 495-515.

[22] Gossop M, Darke S, Griffiths P, et al. The Severity of Dependence Scale (SDS): psychometric properties of the SDS in English and Australian samples of heroin, cocaine and amphetamine users. Addiction 1995; 90: 607-14

[23] Ware JE, Kosinski M, Keller SD. A 12-item Short-Form Health Survey: Construction of scales and preliminary tests of reliability and validity. Med Care 1996; 34: 220-33.

[24] Marsden J, Gossop M, Stewart D, et al. The Maudsley Addiction Profile (MAP): a brief instrument for assessing treatment outcome. Addiction 1998; 93: 1857-68.

[25] Stimson GV, Jones S, Chalmers C, Sullivan D. A short questionnaire (IRQ) to assess injecting risk behaviour. Addiction 1998; 93: 337-47.

[26] Gossop M, Marsden J, Stewart D, et al. The National Treatment Outcome Research Study in the United Kingdom: six-month follow-up outcomes. Psychol Addict Behav 1997; 11: 324-37.

[27] Bland JM. An introduction to medical statistics. $3^{\text {rd }}$ ed. Oxford: Oxford University Press 2000

[28] Flynn PM, Craddock SG, Hubbard RL, Anderson J, Etheridge RM. Methodological overview and research design for the Drug Abuse 
Treatment Outcome Study (DATOS). Psychol Addict Behav 1997; 11: 230-43.

[29] Darke S. Self-report among injecting drug users: a review. Drug Alcohol Depend 1998; 51: 253-63.

[30] Neale J, Robertson M. Comparisons of self-report data and oral fluid testing in detecting drug use amongst new treatment clients. Drug Alcohol Depend 2003; 71: 57-64.

[31] Gossop M, Marsden J, Stewart D. NTORS at one year: the National Treatment Outcome Research Study - changes in substance use, health and criminal behaviour one year after intake. London: Department of Health 1998.

[32] Smith K, Flatley J. Drug misuse declared: findings from the 2010/11 British Crime Survey. England and Wales. London: Home Office 2011.

[33] Gossop M, Moos R. Substance misuse among older adults: a neglected but treatable problem. Addiction 2008; 103: 347-8.

[34] Ross J, Teesson M, Darke S, et al. The characteristics of heroin users entering treatment: findings from the Australian Treatment Outcome Study (ATOS). Drug Alcohol Rev 2005; 24: 411-8

[35] Flynn PM, Brown BS. Co-occurring disorders in substance abuse treatment: issues and prospects. J Subst Abuse Treat 2008; 34: 3647.

[36] Watkins KE, Hunter SB, Wenzel SL, et al. Prevalence and characteristics of clients with co-occurring disorders in outpatient substance abuse treatment. Am J Drug Alcohol Abuse 2004; 30: 749-64.

[37] Weaver T, Madden P, Charles V, et al. Comorbidity of substance misuse and mental illness in community mental health and substance misuse services. Br J Psychiatry 2003; 183: 304-13.

[38] McKeganey N, Bloor M, Robertson M, Neale J, MacDougall J. Abstinence and drug abuse treatment: Results from the Drug Outcome Research in Scotland study. Drugs (Abingdon Engl) 2006; 13: 537-50.
[39] House of Lords Select Committee. No vaccine, no cure: HIV and AIDS in the United Kingdom. Select Committee of HIV and AIDS in the United Kingdom 2011. Available at: http://www.publications.parliamen t.uk/pa/ld201012/ldselect/ldaids/188/18802.htm [Accessed: 06 Oct 2011].

[40] EMCDDA. Polydrug use: patterns and responses. Lisbon: European Monitoring Centre for Drugs and Drug Addiction 2009. Available at: http://www.emcdda.europa.eu/attachements.cfm/att_9 3217 EN EMCDDA SI09 polydrug\%20use.pdf

[41] Millā $\mathrm{T}_{\text {, }}$ Donmall $\mathrm{M}$, Jones A. Treatment effectiveness: demonstration analysis of treatment surveillance data about treatment completion and retention. London: National Treatment Agency for Substance Misuse 2004.

[42] Booth RE, Corsi KF, Mikulich-Gilbertson SK. Factors associated with methadone maintenance treatment retention among streetrecruited injection drug users. Drug Alcohol Depend 2004; 74 177-85.

[43] Cady ME, Winters KC, Jordan DA, Solberg KB, Stinchfield RD. Motivation to change as a predictor of treatment outcome for adolescent substance abusers. J Child Adolesc Subst Abuse 1996; 5: 73-91.

[44] Erickson JR, Stevens S, McKnight P, Figueredo AJ. Willingness for treatment as a predictor of retention and outcomes. J Addict Dis 1995; 14: 135-50.

[45] Gossop M, Stewart D, Marsden J. Treatment process components and heroin use outcome among methadone patients. Drug Alcohol Depend 2003; 71: 93-102.

[46] Joe GW, Simpson DD, Broome KM. Effects of readiness for drug abuse treatment on client retention and assessment of process. Addiction 1998; 93: 1177-90.

[47] Simpson DD, Joe GW, Rowan-Szal GA, Greener JM. Drug abuse treatment process components that improve retention. J Subst Abuse Treat 1997; 14: 565-72. 